\title{
Enhanced Inhibition of Corrosion of Mild Steel by Triazole Derivative in Presence of Copper Ions
}

\author{
B.A.AL Jahdaly ${ }^{1, *}$, M. I. Awad ${ }^{1,2}$ \\ ${ }^{1}$ Chemistry Department, Faculty of Applied Sciences, Umm Al-Qura University, Makkah Al- \\ Mukarramah, Saudi Arabia \\ ${ }^{2}$ Department of Chemistry, Faculty of Science, Cairo University, Cairo, Egypt \\ *E-mail: bajahdali@uqu.edu.sa
}

doi: $10.20964 / 2016.07 .37$

Received: 22 February 2016 / Accepted: 28 April 2016 / Published: 4 June 2016

The inhibition of the corrosion of mild steel in $0.5 \mathrm{M} \mathrm{H}_{2} \mathrm{SO}_{4}$ solution by 5-(4-Pyridyl)-1H-1,2,4triazole-3-thiol (PTT) compound both in the presence and absence of copper ions has been studied using potentiodynamic measurements. It has been found that copper ions significantly enhance the inhibiting action of PPT. For instance, while the inhibition efficiency in the presence of $0.15 \mathrm{mM}$ PTT is $23 \%$, it is tripled when a $0.05 \mathrm{mM}$ of copper ions is added, pointing to the significant synergism between the adsorption of PTT and copper ions. The synergistic parameter was found to equal 2.39 in the presence of $0.15 \mathrm{mM}$ PTT $+0.05 \mathrm{mM} \mathrm{Cu}^{2+}$. The PTT acts as a mixed type inhibitor both in the presence and absence of copper ions, and it follows Langmuir adsorption isotherm.

Keywords: Corrosion inhibitor, Langmuir isotherm, Mild steel, Synergism, Adsorption, copper ions

\section{$\underline{\text { FULL TEXT }}$}

(C) 2016 The Authors. Published by ESG (www.electrochemsci.org). This article is an open access article distributed under the terms and conditions of the Creative Commons Attribution license (http://creativecommons.org/licenses/by/4.0/). 